\title{
A case with unilateral hypoglossal nerve injury in branchial cyst surgery
}

\author{
Sudipta Kumer Mukherjee ${ }^{1 *}$, Chandra Bidhan Gowshami ${ }^{2}$, Abdus Salam $^{3}$, Ruhul Kuddus ${ }^{3}$, Mohshin Ali Farazi ${ }^{1}$ and \\ Jahid Baksh ${ }^{4}$
}

\begin{abstract}
An 11 years old boy came, with complain of mild dysarthria. Examination revealed marked hemiatrophy of left side of the tongue. Five months back he underwent ipsilateral branchial cyst operation. To our knowledge, no case was reported. After branchial cyst operation if there is any residual remnant chance of recurrence is very high.
\end{abstract}

Keywords: Hemiatrophy, Hypoglossal nerve, Brancial cyst

\section{Introduction}

Injury of the hypoglossal nerve is a recognized complication following soft tissue surgery in the upper and anterior part of the neck [1,2], and [3]. Among 100 cases of hypoglossal nerve palsy (33 bilateral) reported by Keane [4], five cases were the result of a surgical procedure: for clival tumors in 2 cases, and carotid endarterectomy and a tonsillectomy in 1 case each, one case was not specified.

In this series in most patients, 12th-nerve involvement was asymptomatic or a minor component of dysarthria. On the contrary acute 12th-nerve transection causes early and late serious oral problems in children [5].

Branchial cleft (branchiogenic) cysts are congenital epithelial cysts, which arise on the lateral part of the neck from failure of obliteration of the second branchial cleft [6]. Their location makes them prone for 12thnerve lesions, but literature mentions are scarce.

\section{Case report}

An 11 years' old boy was operated because of a branchial cyst. The cyst was not infected but the surgeon faced the problem of tissue retraction during operation. One week after operation deviation of the tongue was noted and examination revealed marked atrophy of the ipsilateral side of the tongue. Electromyography revealed partial 12th-nerve injury. Explorative surgery of the

\footnotetext{
*Correspondence: neudipta@gmail.com

'Dept. of Neurosurgery-Shaheed Sheikh Abu Naser Hospital (SSANSH)Khulna-Bangladesh

Full list of author information is available at the end of the article
}

hypoglossal nerve was regarded not to be indicated. Improvement was not noted six months after operation.

\section{Conclusion}

Hypoglossal nerve palsy may be caused by tumors and cysts in the neck, but can also be caused by surgery. It is important to note securely the preoperative situation.

\section{Consent}

Written informed consent was obtained from the patient for publication of this case report and accompanying images. A copy of the written consent is available for review by the Editor-in-Chief of this journal.

\section{Authors information}

1. Sudipta Kumer Mukherjee- Junior consultant-MS (neurosurgery).- Dept of Neurosurgery-Shaheed Sheikh Abu Naser Hospital (SSANSH)-Khulna-Bangladesh.

2. BC Gowshami-Assistant Professor - MD(Cardiology)- Dept of Cardiology-Shaheed Sheikh Abu Naser Hospital (SSANSH)-Khulna-Bangladesh.

3. Abdus salam- Junior consultant -MD (neurology)Dept of Neurology-Shaheed Sheikh Abu Naser Hospital (SSANSH)-Khulna-Bangladesh.

4. Ruhul kuddus -Assistant Professor-MD(Neurology). Dept of Neurology-Shaheed Sheikh Abu Naser Hospital (SSANSH)-Khulna-Banglaesh.

5. Mohshin Ali Farazi -MS(neurosurgery). Registrar Dept of Neurosurgery-Shaheed Sheikh Abu Naser Hospital (SSANSH)-Khulna-Banglaesh. 


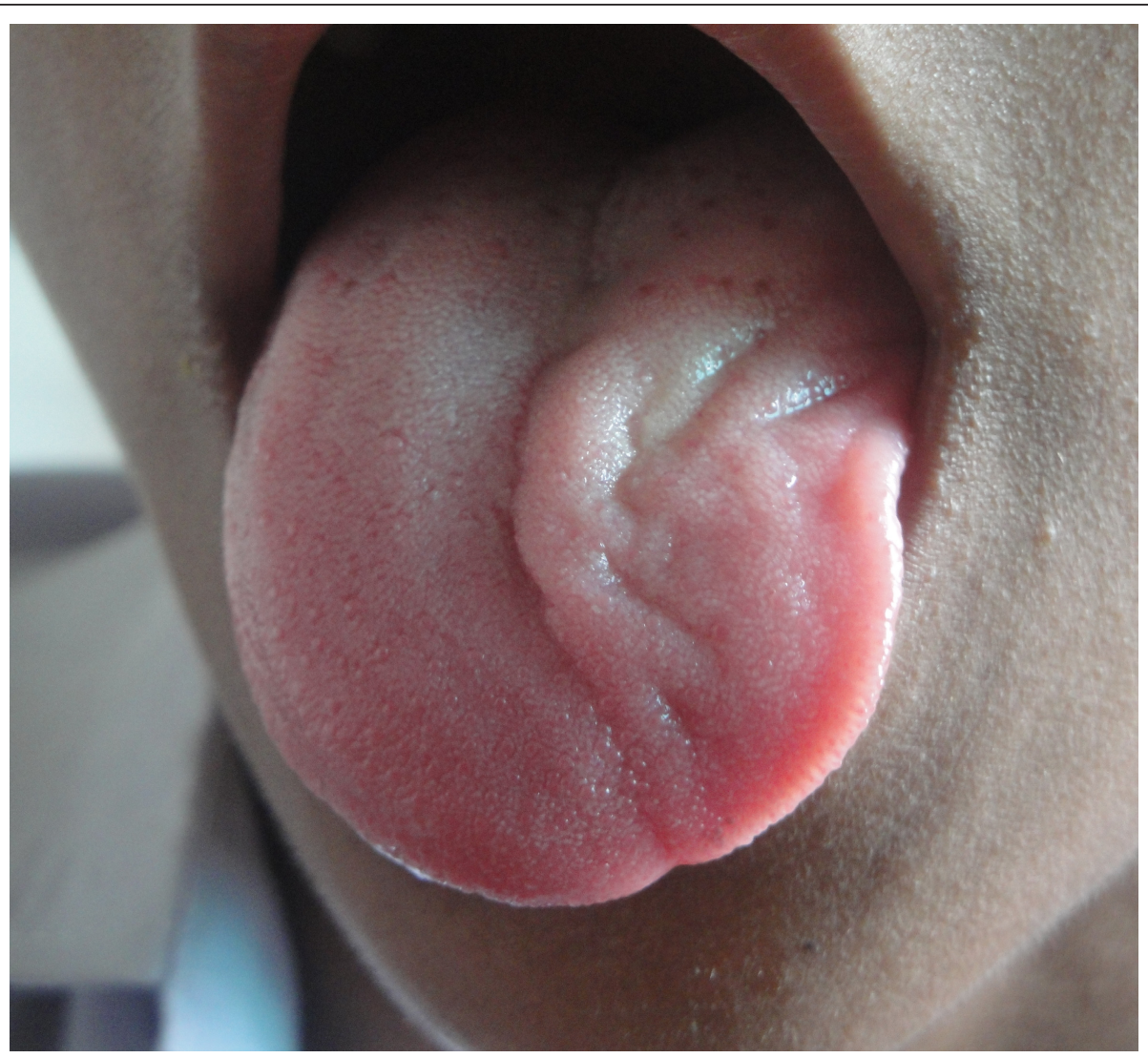

Figure 1 Show marked hemiatrophy of tongue after injury of hypoglossal nerve.

6. Jahid Baksh -Assistant professor -MS(Paediatric surgery)-Dept of Paediatric Surgery- Khulna Medical college Hospital - Bangladesh.

\section{Acknowledgements}

We thank Dr. Selina Daisy (Neurologist) who provided active help during EMG examination.

\section{Author details}

${ }^{1}$ Dept. of Neurosurgery-Shaheed Sheikh Abu Naser Hospital (SSANSH)Khulna-Bangladesh. ${ }^{2}$ Dept. of Cardiology-Shaheed Sheikh Abu Naser Hospital (SSANSH)-Khulna-Bangladesh. ${ }^{3}$ Dept. of Neurology-Shaheed Sheikh Abu Naser Hospital (SSANSH)-Khulna-Bangladesh. ${ }^{4}$ Dept. of Paediatric SurgeryKhulna Medical College Hospital (KMCH) - Bangladesh.

\section{Authors' contributions}

SKM is the chief author who deals the patient clinically, BCG draws SKM attention for this case, AS \& RK perform EMG, MAF help SKM in every aspect and JB take care of this patient preoperatively. All authors have read and approved the final manuscript.

\section{Competing interests}

The authors declare that they have no competing interests.

Received: 6 July 2011 Accepted: 1 February 2012

Published: 1 February 2012

\section{References}

1. Mitroi M, Dumitrescu D, Simionescu C, Popescu C, Mogoantă C, Cioroianu L, Surlin C, Căpitănescu A, Georgescu M: Management of second branchial cleft anomalies. Rom J Morphol Embryol 2008, 49(1):69-74.

2. Swift TR: Involvement of peripheral nerves in radical neck dissection. Am J Surg 1970, 119:694-698.

3. Sengupta DK, Grevitt, Mehdian SMH: Case report. Hypoglossal nerve injury as a complication of anterior surgery to the upper cervical spine. European Spine Journal 1999, 8:78-80.

4. Keane JR: Twelfth-nerve palsy. Analysis of 100 cases. Arch Neurol 1996, 53:561-566.

5. Blaauw G, Sauter $Y$, Lacroix CLE, Slooff ACJ: Hypoglossal nerve transfer in obstetric nerve palsy. J Plast Reconstruct Aesthet Surg 2006, 59:474-478.

6. Wagner AM, Hansen RC: Neonatal skin and skin disorders. In Pediatric Dermatology.. 2 edition. Edited by: Schachner LA, Hansen RC. New York, NY: Churchill Livingston; 1995:291-293, Vol..

doi:10.1186/1749-7221-7-2

Cite this article as: Mukherjee et al:: A case with unilateral hypoglossal nerve injury in branchial cyst surgery. Journal of Brachial Plexus and Peripheral Nerve Injury 2012 7:2. 